\title{
IMPROVING THE STUDENTS'READING COMPREHENSION TRHOUGH QUESTION AND ANSWER RELATIONSHIP (QAR) READING STRATEGY
}

\author{
Prihatin Pujiastuti \\ Universitas Pamulang, Banten \\ dosen01119@unpam.ac.id
}

\begin{abstract}
This research investigated the use of Question and Answer Relationship Reading Strategy in increasing the students' reading comprehension achievement. The research aimed to find out to what extent the improvement of the students' reading comprehension achievement after being treated using Question and Answer Relationship (QAR) reading strategy. This research was conducted at the grade XII students of SMK Sasmita Jaya 2, Tangerang Selatan. This reaseach administrated cluster random sampling in taking the sample then decided two classes as the samples, one class was treated using QAR reading strategy and the other class was not. The method of the research was quantitative research under quasy experimental research. The result of the research shows that there was significant improvement of their reading comprehension after being treated using QAR reading strategy and there was also significant difference between the the students who were treated using QAR reading strategy and the students who were not.
\end{abstract}

Keyword : reading strategy, Question and answer relationship,

\section{Introduction}

Reading is very important for students' activity. By reading, the students would be able to acquire knowledge that is fundamental to their intellectual growth. They become experts in their fields through reading a lot.

Goodman (1988) argued that reading was an active and creative process in interpreting a message based of his/her previous knowledge, predicts and anticipates subsequent rhetorical strategy and information. In this case, in doing reading, the readers need to activate their background knowledge, arrage the new information, make prediction and use appropriate strategy to get the comprehension.

In English lesson, reading is one of the language skills that must be taught besides the other skills namely listening, speaking and writing. The target of reading lesson is comprehension. Comprehension cannot be obtained all of sudden. However, it needs a process and strategy as well as hard effort.

Furthermore Harvey and Goudvis (2007) stated that the meaning of comprehension was when the readers thought not only about what they were reading but about what they were learning. The 
reader built their store of knowledge when they constructed meaning, and along with knowledge must come understanding.

Meanwhile Snow (2002) defined reading comprehension as the process of simultaneously extracting and constructing meaning through interaction and involvement with written language. Both extracting and constructing emphasize the the students to comprehend the text as a determinant of reading comprehension. He added that there were three elements entailed comprehension, namely; The reader, the text, and the activity. The reader is student who is doing the comprehension; the text is the material that should be comprehended; and the activity is the process done to achieve comprehension.

In addition, Tomskin (2011) argued that comprehension was the level of understanding of a text or message. This understanding was achieved by the interaction between the words written and the knowledge triggered outside the text or message. Furthermore, Pardo (2004) added that reading comprehension was a process in which readers constructed meaning by interacting with text through the combination of prior knowledge and previous experience, information in the text, and the stance the reader took in relationship to the text. Similar with Pardo, Bunner (2002) said that reading comprehension was the ability to interact with words and ideas on the page in order to understand what the writer said. The reader needs to make the meaninful interpretation of the written language, the text and the situation in which the text is read.

Regarding with the comprehension, Craik and Lockhart (2009) proposed the theory that reading comprehension involves two levels of processing namely: shallow or low-level processing and deep or high-level processing.

Shallow or low level processing involves sounds, structural and phonemic recognition, word and sentence structure, while deep processing includes semantic processing which covers the meaning of a word and relates to similar words.

To achieve comprehension there are some strategies which can be applied by a teacher in the class. And there are also some efforts that should be done by students in order to achieve comprehension. It means that there should be a good cooperation between the students and the teacher to achieve comprehension in reading. The teacher applies some good strategies and the students should follow the rules of the strategies kindly in order to reach the comprehension in reading.

There are many reading strategies that can be applied by the students to improve their comprehension for example Question and Answer Reading Strategy (QAR). QAR stands for Question and Answer Relationship. This strategy is developed by T. E. Raphael (1986). She proposed three comprehension strategies namely: locating information that showing text structures, organizing the information and determining the inference between the lines required. 
QAR shows the relationship between questions and answers. It helps the students how to categorize different types and levels of questions which inculedes Right There, Think and Search; the Author and You and On My Own questions.

Bouchard (2005) stated that QAR strategy teaches students that there are two broad sources of information for answering question: the text and their background knowledge. Thus QAR encourages the students to be aware to both information either from the text or from their own background knowledge.

Additionally there were some researchers who conducted the researches to investigate the effectiveness of QAR reading strategy in improving students reading comprehension. Kinninburg and Prew (2010) in their research indicated that if QAR strategy implemented effectivelly could increase comprehension of young students and provide a strong fondation for reading comprehension. Meanwhile Cummines at al (2012) investigated that the students became more dilligent in their effort to find the correct answers in academic comprehension tasks including test. More over Peng et al. (2013) in their research found that the students became more confident in answering comprehension questions after applying the strategy.

Raphael (2004) explained that QAR's question based on text and knowledge. Question based on text are classified into Right There and Think and Search. The words used to make up the questions and answers are right there in the same sentences of the text, while in Think and Search, to answer the questions, the students need to relate and search across the text for relevant information. Meanwhile questions based on knowledge are classified as Author and You and On My Own. The answers of the questions in Author and You and On My Own, can be provided from the readers' own background knowledge since the information to answer the questions are not available in the text. Therefore the ability to activate their background knowledge will highly influence the students in answering the question of this part.

Based on the introduction above the research questions are formulated as follows:

1. Is there any significant improvement in the student's reading comprehension achievement after being applied using QAR reading strategy ?

2. Is there any significant difference on reading comprehension achievement between the students who are thought using QAR Reading strategy and the students who are not?

\section{METHOD}

The quantitative research
approach under the quasi experimental research using pre test and post test was conducted in this study. There were two variables applied on this study namely independent variable and dependent variable. It was reading comprehension achievement as the dependent variable and reading strategy as independent variable. QAR strategy was administered to 
experimental group while the control group were not treated using a certain strategy, or in other words they were thought using conventional strategy.

The study was designed into three step procedures, namely: pre-test, treatment, and post-test. A pre-test was given to either the experimental or control group to know the students' level of comprehension before treatment. Then the experimental group was treated using QAR reading strategy while the control group was not.

After conducting the treatment to the experimental group, the researcher administred post test to both experimental and control group. Post-test was given to measure the different score of the both groups before and after treatment, and also to measure the difference score of reading comprehension between the students of the experimental and the control group after the treatment. The post - test was administered after the treatment. In order to find out the significance between the pretest and posttest, the writer analyzed the data by using SPSS 20 .

\section{FINDING AND DISCUSSION Finding}

This study was conducted for the third grade students of SMK Sasmita Jaya 2, Tangerang Selatan. There were seven meetings done for this study (including pre-test and post-test). Pre-test was given to the students at the first meeting before the implementation of Question and Answer Relationship reading strategy, meanwhile the post test was conducted to know the students' reading comprehension score after treatment. Both of the sample class: experimental and control class were administered the pre test and post test. The data bellow shows the different score of pre test - post test of the experimental group and the control group .

Table 1. Descriptive Studies

\begin{tabular}{c|c|c|c|c|c}
\hline & $\mathrm{N}$ & Minimum & Maximum & Mean & Std. Deviation \\
\hline Pre test experiment & 25 & 45 & 70 & 58,52 & 6,312 \\
\hline Post test experiment & 25 & 60 & 85 & 72,64 & 6,720 \\
\hline Pre test control & 25 & 30 & 73 & 57,96 & 10,110 \\
\hline Post test contol & 25 & 35 & 75 & 61,04 & 9,667 \\
\hline Valid N (listwise) & 25 & & & & \\
\hline
\end{tabular}

The table above shows the result of the pre test and the post test score of the experimental class and the control class. The mean score of pre test of experimental class is 58,52 and the mean score of post test is 72.65. So there is about 14.12 point of improvement score after being treated using QAR reading strategy. Meanwhile score of the pre test of the control class 57.96 and the mean score of post test is 61.04 . The improvement score is about 3.08. There was no significant improvement for the class who are not treated using QAR reading strategy. The class was taught using conventional strategy. 
This study also investigated of the students on their reading that there is significant improvement comprehension based on the following table:

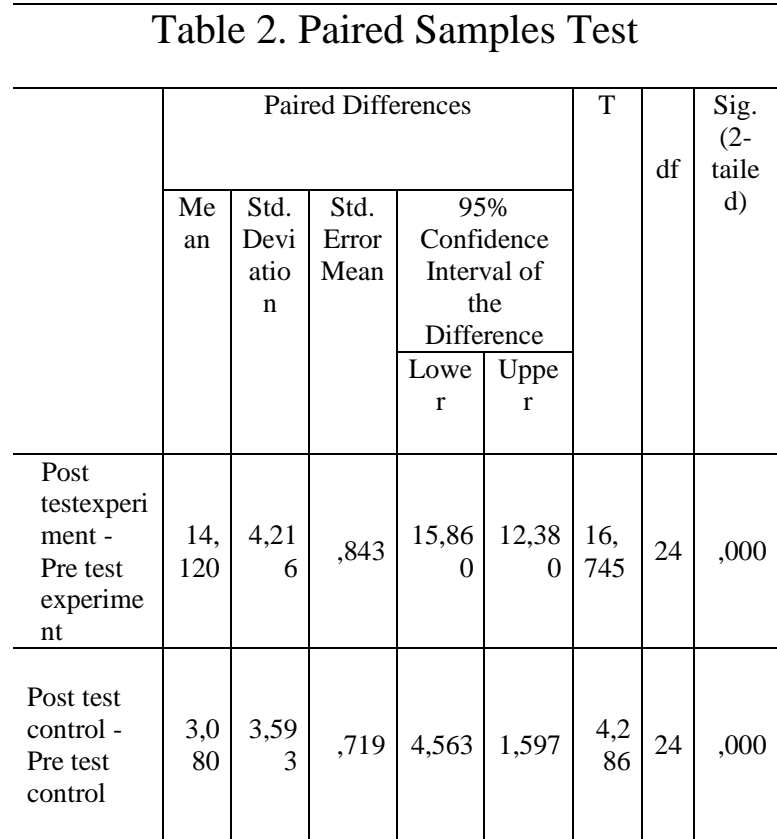

there is significant improvement of the students' reading comprehension.

Based on the table above, the output pair 1 shows the sig value is 0.000 which is under $\alpha=$ 0.05. It means that $H_{0}$ is rejected and $H_{1}$ is accepted. From the critical value approach, the data shows that t-value is 16,746 which is higher than $\mathrm{t}$ table $=1.711$. It emphasizes that assumption that $H_{0}$ is rejected and $H_{1}$ is accepted.

From the mean score, the p- value approach and critical value approach, the interpretation is that there was significant improvement on the student's reading comprehension achievement after the treatment of QAR reading strategy applied. The data shows that the sig. value 0.000 is lower than 0.05 and the $\mathrm{F}$ statistic is 2.362 which is lower than $\mathrm{Fa}$ ( 3.403). It emphasizes the result that Ho is accepted and $\mathrm{Ha}$ is rejected, so the conclusion of the data is that

being treated using QAR reading strategy

Moreover the descriptive statistics clearly states about the difference. The data shows that the maximum result of the post test of the experiment class is 85 meanwhile the maximum post test score of the control class is 75 . The mean score of experiment class is 72 , 64 which is higher than the mean of the control class $(61,04)$. It shows that there is about 11,04 point difference of the both classes. Then it can be concluded that there is there is significant difference on the reading comprehension between the students who are taught using QAR reading strategy and the students who were 
not treated using that strategy or in other words they were taught using conventional strategy.

\section{DISCUSSION}

There are two main points that had been considered to be the important results of this research; (1) the effect of QAR reading strategy in improving the students' reading comprehension, (2) the difference between QAR reading strategy and Conventional strategy in improving the students' reading comprehension achievement.

Referring to the first research question, whether there is or not significant improvement on the students' reading comprehension achievement for the grade XII students at SMK Sasmita Jaya who were taught using QAR reading strategy, the finding of the research shows that there is significant improvement on the reading comprehension achievement after being given the treatment of QAR strategy. It is proven by the result of SPSS analysis that the sig value is 0.000 (lower than $\alpha=0.05$ ) and $t$ value is 16,745 ( higher than t table = 1.711). It means that $H_{0}$ was rejected and Ha was accepted. The interpretation is that there is significant improvement on the students' reading comprehension achievement after being treated using QAR strategy.

This finding is linear with the previous research done by some researchers such as Peng, Hoon, Khoo, Joseph (2007) who investigated the impact of questionanswer-relationships on reading comprehension achievement. Their research had shown that QAR strategy provided students to systematically analyze the task demands of different question provided, which in turn could improve their comprehension on reading. The quantitative data analysis also showed that more than half of the students taught using QAR strategy felt more confident in answering comprehension questions.

\section{Meanwhile} in comprehending reading, students also need be guided to answer any kinds of questions that relate to the content. QAR guides the students to answer four types of questions that help them to get better comprehension. In applying this strategy the reseacher found that the students also became more aware of the text because they were encouraged to activate their background knowledge to connect their shcemata and to the text they were reading since the comprehension means not only comprehend the text, but also to activate their experience and background knowledge. Besides activating their schema, by applying this strategy, the students were also more familiar to think critically to answer the type of question number four namely: the author and me, and the students were trained to apply critical thinking and making prediction.

This finding also emphasizes the theory proposed by the designer of the strategy, Taffy Rafael (2011) that QAR encourages the basis for teaching three comprehension strategies namely: locating information that showing text 
structures, organizing of information, and determining or inferencing reading between the lines that are required.

In QAR, the students were supposed to activate their background knowledge by answering the type of question number four, that is the Author and Me. The students got the comprehension by answering four types of question.

\section{CONCLUSION}

First, the application of QAR reading strategy in reading lesson can improve the students' reading comprehension achievement. The improvement has been shown by the significant increase of the students' score after the treatment. The findings are equal with a number of the previous studies of the effectiveness of QAR reading strategy.

Second, QAR reading strategy that was applied properly significantly improve the students reading comprehension. From the output of SPSS, the data shows that there was significant improvement of the students' reading comprehension achievement compared with the control class who was taught using the conventional technique. The application of QAR reading strategy showed 11,04 point differences of the result between the experimental class and the control class. On the other word, the students who applied QAR reading strategy got 11,04 points higher than the conventional strategy.

The researcher examined in the classroom that the students in QAR reading strategy became more familiar with the types of questions that helped them to answer the questions correctly then finally improved their comprehension toward the text they read.

Teaching reading in vocational school could be different from others. The appropriate strategy should be applied in order to reach comprehension. QAR reading strategy is one way of the strategies that can be applied to teach reading to increase the student's comprehension. The researcher suggests the other researchers to use this strategy and compare with other strategies or combine the QAR reading strategy with other strategies to improve the students' reading comprehension achievement.

\section{REFERENCES}

Antony, H.M, \& Taffy E Raphael. (2004). Content Area Reading and Learning: Using questioning strategies to promote Students's active comprehension of content Area Material. Lawrence Erlabaum Associates, publishers: Mahwah New Jersey.

Brown, H.D. (2004). Language assessment principle and classroom practice. Pearson Education, Inc.

Bouchard,

M.

(2005).

Comprehension strategies for English language learners. Scholastic Inc. USA.

Bunner, T. L. (2002). Content Area Learning Strategies To Improve The Learning of Second Language Learners. Unpublished master's project, 
California State University, Sacramento.

Cain, Kate \& Oakhill, Jane. (2009). The Behavioral and Biological Foundation of Reading Comprehension. Guilford Press.

Cummins, S., Streif M., \& Ceprano, M., (2012). Understanding and applying the QAR Strategy To Improve Test Score. Journal of Inquiry \& and action in Education.

Goodman, K.S. (1988). The Reading Process: Interactive Approaches to second language reading. New York: Cambridge University Press

Harmer, J. (2001) How to teach English. Addison Wesley Longman.

Harvey, S., \& Anne G. (2007). Trategic that work teaching comprehension for understanding and engagement. Stenhouse Publisher.

Kinniburgh, L.H. (2010). Question And Answer Relationship In The Primary Grades: Laying The Fondation For Reading Comprehension.

International Journal of Early Chilhood Special Education (INT- JECSE)
Pardo, L. S. (2004). What every teacher needs to know about comprehension. The Reading Teacher, 58(3), 272-280.

Peng. R., F K, Isabel M J. (2007). Impact of Question and Answer Relationship on Reading Comprehension. Pei Chun Public School and Marymount Convent Ministery of Education, Singapore.

Raphael, T.E..(1986).Teaching Question Answer Relationships, revisited. The Reading Teacher (39) 6

Raphael, T.E .(2011).Accessible Comprehension Instruction Through QAR . University of Illionis at Chicago and School Rise LLC.

Sandra S. Prew. (2010). Question And Answer Relationship In The Primary Grades: Laying The Foundation For Reading Comprehension.

International Journal of Early Childhood Special Education (INT-JECSE), June 2010, 2: 1

Snow, C.E. (2002). Reading for understanding: Toward an $R \& D$ program in reading comprehension. Santa Monica, CA: Rand. 
